\title{
Sex Differences in the Stability of Self-Regulation Across Childhood
}

\author{
Michelle Anne Coyne • Jamie C. Vaske • \\ Danielle L. Boisvert • John Paul Wright
}

Received: 7 October 2014 / Revised: 10 January 2015 / Accepted: 19 January 2015 /

Published online: 25 February 2015

(C) Springer International Publishing AG 2015

\begin{abstract}
Purpose Self-regulation has gained wide-spread attention across a number of social science disciplines in recent years. It is clear that a lack of self-regulation is related to a host of behavioral, social, and criminogenic outcomes. Questions remain, however, regarding between and within sex differences in the change and stability of selfregulation across time.

Methods Using data from a large representative sample of children in the USA, we employed latent class growth analyses to examine the patterns of development in selfregulation in males $(N=10,293)$ and females $(N=9873)$ over a 5 -year time span from kindergarten through fifth grade.

Results Results indicated that females had a higher mean level of self-regulation across time and that both the male and female samples yielded three classes. In both samples,
\end{abstract}

Electronic supplementary material The online version of this article (doi:10.1007/s40865-015-0001-6) contains supplementary material, which is available to authorized users.

M. A. Coyne $(\square)$

School of Criminal Justice, University of Cincinnati, ML 210389, 3150-B Edwards 1, Clifton Avenue, Cincinnati, OH 45221-0389, USA

e-mail: coyneme@mail.uc.edu

J. C. Vaske

Department of Criminology and Criminal Justice, Western Carolina University, 410A Belk, Cullowhee, NC 28723, USA

e-mail: jvaske@email.wcu.edu

D. L. Boisvert

College of Criminal Justice, Sam Houston State University, A-208, Huntsville, TX 77341, USA

e-mail: dxb014@shsu.edu

J. P. Wright

School of Criminal Justice, University of Cincinnati, ML 210389, 5343-A CRC, Clifton Avenue, Cincinnati, OH 45221-0389, USA

e-mail: wrightww@ucmail.uc.edu

J. P. Wright

Social and Behavioral Sciences, King Abdulaziz University, Jeddah, Saudi Arabia 
all three classes remained relatively stable across time, with particular stability in the lowest self-regulatory groups.

Conclusion There was little change in mean self-regulatory behavior regardless of class membership or sex. These findings have important implications for early identification of and early intervention with children exhibiting self-regulatory problems.

Keywords Self-regulation $\cdot$ Sex differences $\cdot$ Stability $\cdot$ Change $\cdot$ ECLS-K

\section{Introduction}

Self-regulation and related concepts such as self-control, impulsivity, and anger regulation have been cited as some of the strongest predictors of concurrent and future social and behavioral problems in both criminology and psychology [11, 46, 52]. In traditional criminological literature, many studies have focused on self-control measured in terms of impulsivity, risk-taking, insensitivity towards others, and preference for physical over mental activities [21, 22]. Self-regulation is a similar but broader concept that has been defined a variety of ways by different scholars and theories [7]. One view of selfregulation is that it is the ability to control or direct one's attention, emotion, cognition, and behavior in ways that allows for successful adaptation to environmental demands, achievement of goals, and compliance with group norms [39, 47]. This is a broad conceptualization of self-regulation that incorporates a number of processes related to attention and regulation, such as attention shifting, concentration, persistence, organization, flexibility, self-control, impulsivity, risk taking, effortful control, and appropriate expression of emotion, cognition, and behavior. A broad definition of self-regulation is in line with current theoretical perspectives on regulation and research from neuroscience which shows that the same brain regions (i.e., anterior cingulate gyrus, frontal cortex, insula, temporal cortex) are involved in these multiple, interrelated processes $[13,55]$.

Research has shown that individuals with low levels of self-regulation are more likely to have problems with school, employment, relationships, substance abuse, and are more likely to be involved in criminal activities $[2,61,64]$. Poor self-regulation may also predict continuity in criminal activity as Monahan et al. [38] noted that adolescents with impulsivity and aggression suppression issues were most likely to remain persistent offenders in early adulthood. Given the importance of self-regulation to healthy social functioning, investigators have begun to examine the development of self-regulation across the life course. The general findings from the literature are that self-regulation, like self-control and other traits, typically emerges early during toddlerhood and that the ability to self-regulate one's affect, behavior, and attention increases throughout early childhood and becomes moderately stable during middle childhood for the majority of individuals [7, 16, 28, 47]. This type of information has provided theoretical and empirical support for the emergence of early intervention programs that assess and target toddlers' progress towards psychosocial developmental milestones.

While there are a growing number of studies that investigate the development of self-regulation, some questions remain regarding the applicability of self-regulation trajectories within and between sexes. The majority of studies that have assessed whether sex conditions the development of self-regulation have assumed that (1) the development of self-regulation is captured by one trajectory that equally applies 
(more or less) to the population, rather than multiple trajectories explaining selfregulation development for males and females and (2) if multiple trajectories explain the development of self-regulation, the number and shape of the trajectories is the same for males and females.

There are reasons to believe, however, that the development of self-regulation is heterogeneous both within and between sexes. Potential heterogeneity in self-regulation may relate to and help explain differential levels of self-control, impulsivity, and criminal propensity between sexes. Research into other psychological and behavioral constructs has shown that development cannot be clearly summarized by one trajectory, and that the types and/or numbers of developmental trajectories may differ between males and females $([6,17,20,43]$; except see [14]). A clearer understanding of the development of self-regulation within and between sex is important for clinicians who are attempting to identify and treat at-risk children and children with self-regulation problems.

For instance, assuming that the development of self-regulation is the same between males and females could lead to misidentification of at-risk youths and inappropriate intervention approaches. Further, sex differences in the number and shape of selfregulation trajectories could suggest that the causes and consequences of those trajectories may vary by sex, thus further promoting the refinement of sex-specific theories. At this point in the literature though, it is not clear whether the development of selfregulation is sex neutral or sex specific. The current study addresses this gap in the literature by using a semi-parametric group-based modeling approach to examine the number and shape of self-regulation trajectories for males and females in a general population sample of youths from kindergarten until the fifth grade.

\section{The Development of Self-Regulation}

The life-course development of self-regulation has been investigated using a variety of methods and techniques. One way to categorize the development of self-regulation is based upon absolute and relative stability. Absolute stability refers to the lack of change in the mean level of self-regulation between two or more time periods. To say that a behavior exhibits absolute stability over time would indicate that the mean score of selfregulation at time 1 did not statistically differ from the mean score of self-regulation at time 2. Relative stability, on the other hand, examines the rank order position of individuals over time. That is, an individual's self-regulation score at two time periods $\left(X_{1}\right.$ and $\left.X_{2}\right)$ is compared to the mean of the overall sample at time 1 and time $2\left(X_{1}-\bar{X}_{1}\right.$ and $X_{2}-\bar{X}_{2}$ ), with consistency in distance from the mean at each time point reflecting stability. For example, if an individual was in the top $5 \%$ of highest self-regulation scores at time 1 and remained in the top $5 \%$ at time 2 , this would indicate relative stability in self-regulation.

In general, empirical evidence suggests that the average levels of self-regulation may increase during toddlerhood and early childhood, but that self-regulation may begin to exhibit absolute stability as youths move into middle childhood. This is the typical pattern of development of self-regulation for the majority of youths. For example, Raikes and colleagues' [48] analysis of 2441 children showed that self-regulation significantly increased from 14 months of age to 36 months of age. Similarly, other studies have shown that there is positive growth in inhibitory control and the ability to 
delay gratification from ages 2 to 5 [34, 37]. Raffaelli et al.'s [47] study of 646 youths from the National Longitudinal Study of Youths found that self-regulation increased from age 4 to ages $8-9$, but that there was no significant change in the mean levels of self-regulation from ages $8-9$ to ages $12-13$. These findings suggest that the ability and capacity to self-regulate may grow during childhood, but starts to stabilize at around 8 to 9 years of age $[16,39]$.

It is important to note, however, that some studies have shown that absolute stability in self-control emerges around age 5-9 [57], while other studies have shown that selfregulation and its components continue to develop into adolescence and young adulthood [41, 58]. For instance, Turner and Piquero [53] showed that the average levels of self-control increased from ages 5 to 23. The inconsistency in results across studies may be explained by the statistical approach being used. For example, latent class growth models allow the development of self-regulation to unfold across multiple trajectories, with some developmental trajectories being more common than others. Most latent class growth model studies show that there is absolute stability in self-regulation and its components for the majority of individuals, with a moderate percentage of the population (16-28\%) exhibiting changes in the average levels of self-regulation and its components [27, 28, 56]. Thus, self-regulation may be characterized by absolute stability for most individuals, yet there are some individuals that exhibit changes in their mean levels of self-regulation over time.

In terms of relative stability, the research suggests there is a moderate amount of relative stability in self-regulation and its components from childhood into early adulthood for most individuals [1, 47]. For instance, the correlation between selfregulation at multiple time points often ranges from 0.33 to 0.83 , with the majority of correlations being between 0.40 and 0.60 [9, 27, 28, 53]. Similarly, Vazsonyi and Huang's [58] analysis of youths found that there was not significant variation in the linear growth curve slope of self-control from ages 4.5 to 10.5 , indicating that individuals within the sample increased their self-control levels at approximately the same rate. Results from latent class growth models have also shown that children and adolescents' self-regulation may develop along multiple trajectories, but these trajectories may not cross each other $[28,56,57]$; thus, individuals who exhibit self-regulation deficits at later time periods are the same individuals who exhibited problems with self-regulation in early periods of development.

Similar to the results on absolute stability, there is also evidence that there is relative instability in self-regulation for a subset of the population. For instance, Burt et al.'s [9] analysis of African American youths found that $50 \%$ of the sample exhibited significant changes in self-control levels from ages 10 to 14, and in a recent study, Burt et al. [8] also noted a large proportion of instability in impulsivity and risk-taking traits in their sample of people 10-25 years of age. Studies employing linear growth curve models have shown significant variation in the slope for self-regulation measures as well [8, 41, 48, 62]. Hay and Forrest's [27] latent class growth models showed that approximately $46 \%$ of the sample exhibited relative instability in self-control from ages 6 to 15 .

Overall, the evidence suggests that, in general, there is absolute and relative stability in self-regulation from childhood to early adulthood for the vast majority of individuals. Yet, there are groups of individuals who experience significant changes in the mean levels of self-regulation over time (absolute instability). Further, these individuals may 
exhibit significant changes in self-regulation relative to their peers (relative instability). These nuances in the literature may be exacerbated when one considers how sex conditions the development of self-regulation, as most researchers have merely used sex or gender as a covariate in their models rather than exploring whether selfregulation develops along different trajectories for males and females.

\section{Sex Differences in the Development of Self-Regulation}

Self-control and social control theorists have argued that females should exhibit higher levels of self-control, relative to males, because females are subjected to higher levels of parental supervision than males and are more likely to be reprimanded for deviant behaviors [21]. In particular, Hagan's power-control theory states that females should exhibit lower levels of risk-taking and greater self-regulation due to the intersection of family structures, gender stereotypes, and parental supervision practices [24, 25]. In patriarchal families, fathers may enjoy higher class positions within the workplace and greater access to resources outside the home, especially due to risky decisions that lead to success for the company or the individual. In contrast, mothers are considered subservient to fathers, and are responsible for child rearing and tending to the family. These gender norms are reproduced within the household to where daughters are expected to stay close to the family to help their mother with household responsibilities, while sons are encouraged to explore the outside world. This approach to childrearing produces a situation where females develop higher levels of self-regulation than males due to their higher levels of supervision, greater detection of risky behavior, and greater punishment for risky behaviors. Thus, power-control theory suggests that there should be sex differences in the average levels of self-regulation because of gender stereotypes and gender differences in monitoring, recognition of deviance, and punishment. While this provides a broad theoretical framework for gender differences in self-regulation, power-control theory and other criminological theories do not give us insight into sex differences in the longitudinal development of self-regulation. For guidance on these issues, we turn to the empirical evidence on sex and the development of self-regulation.

A review of the research on sex differences in the development of self-regulation shows that (a) females typically exhibit higher levels of self-regulation than males over the life course $[12,19,29,30]$, (b) there is a lack of absolute stability in self-regulation early in life for both males and females [37, 48, 58], (c) self-regulation begins to exhibit absolute stability for the majority of individuals as males and females approach middle childhood and adolescence (with some subgroups lacking absolute stability) [47, 49], and (d) self-regulation is characterized by moderate relative stability for both males and females [34]. Studies employing linear growth curve models have also shown that selfregulation or its subcomponents may increase in early childhood, but the rate of change in self-regulation does not significantly vary between sexes [34, 37, 48, 58].

While research has suggested that the development of self-regulation does not vary by sex, there are at least two important limitations to this previous research. First, most of the studies merely used sex or gender as a covariate in the analysis and few studies conducted separate analyses by sex ([27, 48, 49]; except see [34, 47]; but see [39]). Second, previous research has assumed that pooled estimates or single trajectories accurately summarize the development of self-regulation for the entire sample. Research from latent class growth models, however, have shown that the development 
of self-regulation is characterized by multiple trajectories $[27,28,49,56,57]$ and that the use of pooled estimates may provide an inaccurate picture on the development of self-regulation. Thus, the use of single trajectories and the use of sex as a covariate (rather than estimating separate models for males and females) may underestimate heterogeneity in the development of self-regulation.

There are at least two additional reasons why one might expect the development of self-regulation to vary between and within sexes. First, neuroimaging research has shown that there are significant sex differences in the development of brain regions that are implicated in self-regulation [15], and thus, there may be between sex differences in the absolute stability of self-regulation. For instance, Lenroot and colleagues [32, 33] reported that development of the frontal lobe appeared to peak approximately 1 to 2 years earlier for females than males. Raznahan et al.'s [50] analysis of 284 healthy individuals from ages 9 to 22 showed that regions of the frontal lobes were slower to mature (as measured by loss of cortical thickness) for males than for females. These findings suggest that sex may condition the development of self-regulation because there are between sex differences in the development of the brain regions typically linked to self-regulation. Further, it is likely that there are within sex differences in the development of self-regulation because the development of the frontal cortex within males and females may not be homogeneous.

Second, research has shown that there are within and between sex differences in the development of other psychological and behavioral constructs that are related to selfregulation [20,43]. Within sex differences may occur when there are multiple trajectories (rather than one trajectory) that explain the development of a construct within males or females. For instance, Côté and colleagues [14] found that impulsivity and fearlessness was described by multiple trajectories for males and females, suggesting that there is significant within sex variation in the development of those constructs. Between sex differences may be evident when the number, shape, or type of developmental trajectories differs between males and females. Broidy et al.'s [6] latent class growth model of data from six samples found that there were significant sex differences in the number and types of trajectories that best described physical aggression for males and females. For example, the authors found that physical aggression was described by two trajectories for females (one stable, one decreasing) in the Dunedin Multidisciplinary Health and Development Study, but physical aggression patterns were explained by three stable trajectories for Dunedin males. Further, the degree of absolute and relative stability in physical aggression varied between sexes. Dekker et al. [17] also found that (1) multiple trajectories explained the development of depressive symptoms within each sex, (2) the number and type of trajectories characterizing depressive symptoms varied between sexes, and (3) the degree of absolute and relative stability in depressive symptoms differed for males and females. Together, these findings indicate that there may be significant between and within sex variation in the development of self-regulation which may be an important finding for identification and intervention of problem behavior.

\section{Current Study}

Given the limitations of previous research and questions surrounding the absolute and relative stability of self-regulation by sex, the current study examines the development 
of self-regulation from kindergarten to fifth grade among males and females. The current investigation addresses the limitations of previous research by the following: (1) estimating separate models for males and females and (2) employing latent class growth models to examine the development of self-regulation. This approach allows researchers to examine whether there are multiple trajectories that explain the development of self-regulation and whether there are significant differences in the trajectories both within and between sexes.

\section{Methods}

\section{Sample}

This study used data from the Early Childhood Longitudinal Study, Kindergarten Class of 1998-1999 (ECLS-K). The ECLS-K is sponsored by the U.S. Department of Education and the National Center for Education Statistics. With data from over 21,000 children, the ECLS-K is one of the largest nationally representative samples of kindergarten children, parents, teachers, and schools in the USA. A variety of information was collected through parent and child interviews, teacher and school administrator questionnaires, and observations by trained evaluators in the schools. The data provide detailed information about the subjects' school and classroom environments, mental and physical health, home and family relationships and environments, and the child's cognitive, emotional, and social development across early childhood.

The initial data were collected in the fall of 1998 when the children first entered kindergarten. Subsequent data was collected later in the spring of 1999 and then again in both the fall (1999) and spring (2000) of first grade. Follow-up data were collected in the spring sessions of third grade (2002), fifth grade (2004), and eighth grade (2007). In order to ask developmentally appropriate questions, the eighth grade wave used entirely different measures of self-regulation. Therefore, the eighth grade wave was excluded from the current study. More specifically, the current study used the following four waves of data: fall of kindergarten (1998), spring of first grade (2000), spring of third grade (2002), and the spring of fifth grade (2004). As our interest is to examine sex differences in self-regulation, we used the full sample and divided the sample into males and females. This resulted in a sample of 10,293 males and a sample of 9873 females followed from kindergarten through fifth grade.

\section{Measures}

Our measure of self-regulation comes from Gresham and Elliot's [23] Social Skills Rating System (SSRS). The SSRS has been used in a variety of studies that have assessed self-regulation and other related social skills and behaviors [3, 31, 58, 63]. Furthermore, while the scales in the SSRS have been used and combined in many different ways, overall, it has been regarded as both valid and reliable [4, 18, 35]. The ECLS-K is composed of both parent and teacher measures from the SSRS. The parent and teacher measures were moderately correlated at 0.40 in kindergarten and in the first grade. Unfortunately, parent measures were only available in 
kindergarten and first grade, which was insufficient for our analyses. Therefore, we used the teacher-reported SSRS measures across four waves, from kindergarten through the fifth grade. The self-regulation measure is comprised of four SSRS subscales including the following: (1) approaches to learning, (2) self-control, (3) externalizing problem behaviors, and (4) interpersonal skills (see Appendix A for a complete list of items). These scales tap a range of behaviors such as controlling one's temper, responding appropriately to pressure from peers, expressing thoughts and feelings, attentiveness, impulsivity, arguing, disturbing ongoing classroom activities, and fighting among others. Using a Likert scale ranging from 1 (never exhibits this behavior) to 4 (very often/ exhibits behavior most of the time), teachers reported about student behavior at each wave. The mean of these items was then used as the reported score (1-4) on each of the four subscales. Our self-regulation measure is a combination of four SSRS subscales with scores ranging from 4 (very low self-regulation) to 16 (very high self-regulation). ${ }^{1}$

\section{Analytical Plan}

As unique trajectories may be present within the data, latent class growth analyses were used to examine the patterns of change in self-regulation across males and females. Latent class analyses involve estimating a model which identifies unmeasured (latent) classification of individuals based on observed patterns of change in self-regulation. These latent patterns of change are defined by unique growth curves. The selection of the appropriate number of classes is based on fit statistics and classification benchmarks such as the Bayesian Information Criterion (BIC), which is calculated using the loglikelihood value of the model while adjusting for sample size. While there is no specific benchmark for BIC, a value indicating good model fit is generally closer to zero. Other statistics include the entropy value and latent class probabilities. The entropy value measures how clearly classes are defined, with values approaching 1 indicating clear delineation. Similarly, latent class probabilities measure the degree of certainty in placing individuals in certain classes with values approaching 1 indicating the best placement of individuals into estimated classes. Finally, the Lo-Mendell-Rubin (LMR) is used to examine model fit. The LMR test compares a given model $(k)$ to a model with one fewer class $(k-1) . P$ values that are not statistically significant $(>0.05)$ indicate that the $(k-1)$ model is a better fit for the data than the current model $(k)$. These statistics are commonly used when conducting latent class analyses [36, 40, 60].

\section{Results}

The male and female samples were nearly identical across demographics such as age and race (55\% white; $45 \%$ non-white) but were different in mean levels of selfregulation. Table 1 illustrates the mean levels of self-regulation at each wave as well as

\footnotetext{
${ }^{1}$ We recognize that this conceptualization of self-regulation is somewhat broad. However, our measure of selfregulation has strong psychometric properties (alpha=0.85), and factor analyses confirm that these four subscales reflect one unitary construct across time. Furthermore, identical analyses were conducted with the self-control subscale only, and the results were nearly identical to those reported within (and are available upon request).
} 
Table 1 Means, standard deviations, and correlation coefficients of self-regulation from kindergarten through 5 th grade

\begin{tabular}{|c|c|c|c|c|c|c|}
\hline Self-regulation: & Mean & Standard deviation & Kindergarten & 1st grade & 3rd grade & 5 th grade \\
\hline \multicolumn{7}{|l|}{ Males $(N=10,293)$} \\
\hline Kindergarten & 11.93 & 2.25 & 1.00 & $0.50 * * *$ & $0.45^{* * *}$ & $0.39 * * *$ \\
\hline 1st grade & 12.20 & 2.32 & & 1.00 & $0.55 * * *$ & $0.49 * * *$ \\
\hline 3rd grade & 12.15 & 2.30 & & & 1.00 & $0.55 * * *$ \\
\hline 5 th grade & 12.25 & 2.24 & & & & 1.00 \\
\hline Total $(K-5$ th $)$ & 49.21 & 6.83 & & & & \\
\hline Mean $(K-5$ th $)$ & 12.30 & 1.71 & & & & \\
\hline \multicolumn{7}{|c|}{ Females $(N=9873)$} \\
\hline Kindergarten & 12.91 & 2.02 & 1.00 & $0.48 * * *$ & $0.43 * * *$ & $0.36 * * *$ \\
\hline 1st grade & 13.19 & 2.06 & & 1.00 & $0.53 * * *$ & $0.46^{* * *}$ \\
\hline 3rd grade & 13.18 & 2.16 & & & 1.00 & $0.51 * * *$ \\
\hline 5 th grade & 13.36 & 2.01 & & & & 1.00 \\
\hline Total $(K-5$ th $)$ & 53.13 & 6.26 & & & & \\
\hline Mean $(K-5$ th $)$ & 13.28 & 1.56 & & & & \\
\hline
\end{tabular}

${ }^{* * *}$ Indicate that the correlations are statistically significant at the .01 level

the combined mean score across kindergarten through fifth grade for both males and females, separately. The female sample had consistently higher mean levels in selfregulation at each wave. However, the degree of difference varied slightly, with the smallest difference exhibited in the initial (kindergarten) wave, and the largest difference exhibited in the fifth grade. Nonetheless, $t$-tests indicated that self-regulatory differences between males and females at each wave were statistically significant. In general, females exhibited about a one point higher score in mean self-regulation than did males at each wave and in a combined measure of self-regulation averaged across time with females averaging a score of 13.28 and males a score of 12.30 .

Table 1 also displays correlation coefficients for the self-regulation measure across time. These correlation coefficients assess the average stability for the male and female samples and are comparable to those found in prior studies [58]. A repeated measures ANOVA was used to examine absolute stability in the male and female samples. Results from the linear and quadratic tests indicate that self-regulation did exhibit statistically significant change over time in both the male and female samples. We note that statistical significance may be due, in part, to the large sample sizes. These preliminary analyses indicate moderate relative stability in average self-regulation but a lack of absolute stability for both males and females. However, as different trajectories may be present within the male and female samples, relative and absolute stability in self-regulation was also assessed using latent growth class analyses.

Table 2 presents the fit indices for the results from the latent class growth analyses. While the fit indices do not yield a perfectly clear solution, we determine that a threeclass solution was the most appropriate. While there is a considerable drop in entropy and latent probability values when moving from two to three classes, the drop in BIC is greatest when moving from the two-class to three-class solution for both male and 
Table 2 Fit statistics for latent growth class analyses by sex

\begin{tabular}{llllllllllll}
\hline No. of classes & LL (HO value) & BIC adjusted & Entropy & LMR $(p$ value $)$ & Mean LC probabilities & \\
\hline Males & & & & & & & & & & \\
2 & -58409.51 & 116873.57 & 0.64 & 0.00 & 0.87 & 0.90 & & & \\
3 & -57893.95 & 115860.64 & 0.58 & 0.00 & 0.74 & 0.84 & 0.81 & & \\
4 & -57758.24 & 115607.40 & 0.54 & 0.00 & 0.79 & 0.60 & 0.67 & 0.80 & \\
5 & -57659.19 & 115535.23 & 0.50 & 0.11 & 0.77 & 0.73 & 0.57 & 0.56 & 0.62 \\
Females & & & & & & & & & \\
2 & -54379.68 & 108813.55 & 0.71 & 0.00 & 0.93 & 0.86 & & & \\
3 & -53889.70 & 107851.63 & 0.66 & 0.00 & 0.82 & 0.75 & 0.88 & & \\
4 & -53703.27 & 107496.84 & 0.64 & 0.04 & 0.80 & 0.65 & 0.70 & 0.86 & \\
5 & -53633.73 & 1073735.81 & 0.62 & 0.00 & 0.83 & 0.64 & 0.64 & 0.67 & 0.77 \\
\hline
\end{tabular}

females, and the LMR and latent probabilities values still indicate that a three-class solution is acceptable. While the $\mathrm{LMR}^{2}$ value is significant for more than three classes, after the three-class solution, latent probabilities drop into the 0.60 's and continue to drop as more classes are added for both sexes. Thus, given the drop in BIC, latent probabilities, and overall fit, the three-class solution was chosen. Both male and female samples include three distinct groups: a high, medium, and low class - all of which remain relatively stable from kindergarten through fifth grade.

While the class structure is the same for both males and females, there are differences in the mean levels of self-regulation across classes, the distribution of individuals in each class, and the shape of their trajectories. Females had a higher mean level of selfregulation across all three classes. For example, the mean score for the female's highest class was 13.99 as compared to the male's highest class which was 13.52 . The female sample also had a higher proportion of individuals in their highest class $(58.1 \%)$ compared to the proportion of individuals in the highest class for the male sample $(42.2 \%)$ as well as a smaller proportion of individuals in their lowest class $(9.4 \%)$ as compared to the proportion in the male's lowest class (17.7\%). The shape of the trajectories between males and females are similar for the high and the low classes, but the shape is different for the middle class. In females, the middle class exhibits slight increases in self-regulation where males in the middle class exhibit slight decreases in self-regulation. Figure 1 illustrates the latent class trajectories for females and males including their $95 \%$ confidence intervals. The latent class trajectories for both males and females do not overlap and remain distinct across time, indicating relative stability.

Finally, the latent growth class estimates for each class in both the male and female samples are presented in Table 3 . The latent growth class estimates indicate significant and substantive differences in the initial level of self-regulation for all three classes in males and females. However, the slope estimates, while sometimes statistically significant, are substantively minor. In the female sample, two of the three slope estimates are statistically significant yet are small in magnitude. In the highest class, females increased an average of 0.14 points each year and increased only an average of 0.10

\footnotetext{
${ }^{2}$ Recent research indicates that the LMR test tends to overestimate the number of classes [42].
} 


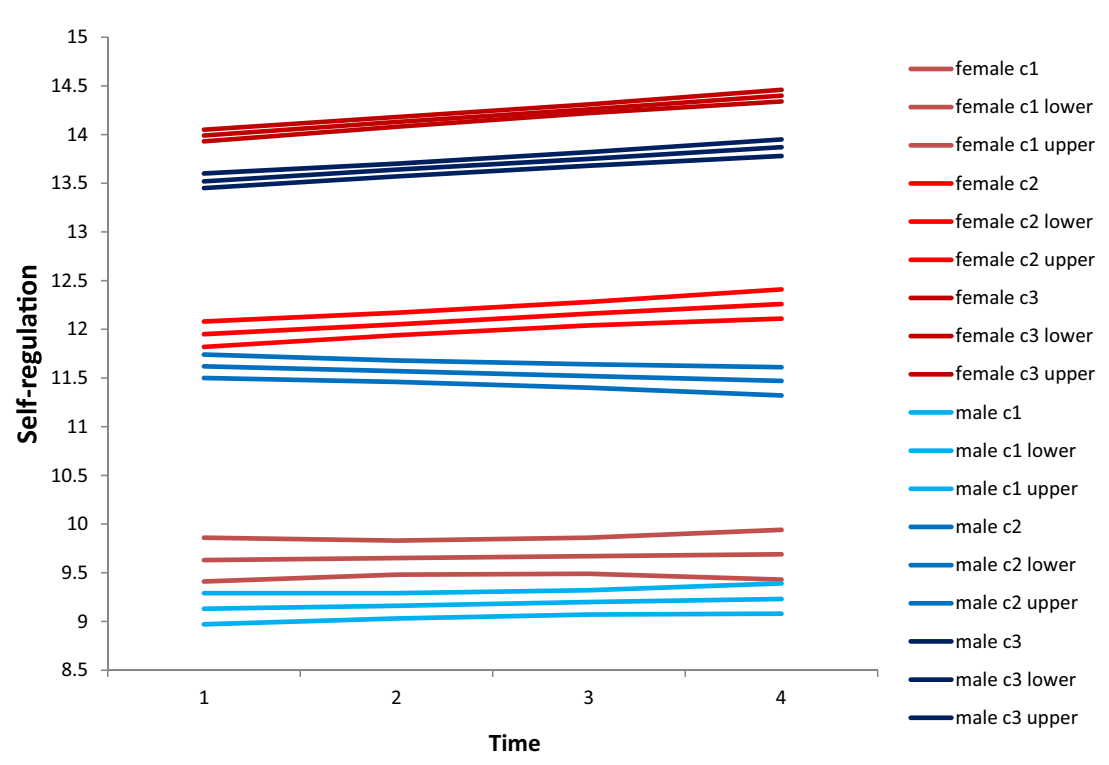

Fig. 1 Male and female self-regulation class trajectories with $95 \%$ confidence intervals

points in the middle class. The slope estimates for the lowest female class were not statistically significant. The results for the male sample were very similar. The high and the middle male classes had significant but very minor average changes in their slopes. The highest male class increased an average 0.12 points in self-regulation each year while the middle class decreased an average of 0.05 points each year. As in the female sample, the lowest male class did not exhibit statistically significant change in slope estimates.

\section{Discussion}

Numerous studies from a variety of disciplines reveal a critical link between poor self-regulation and a variety of social and behavioral problems. As part of that continuing evolution of this body of research, scholars have only recently examined possible sex differences in self-regulatory behavior. As such, the current study sought to add to the literature by using latent class growth analyses to examine sex differences in mean self-regulation and to examine the degree of relative and absolute stability in mean self-regulation from kindergarten through fifth grade.

The latent class growth analyses provide evidence for a three-class solution with three distinct and relatively stable classes for both the male and female samples. The three-class solution is different than other trajectory analyses that have yielded more classes [27, 49, 57]. One possible explanation for this difference in findings may involve the use of teacher reports of behavior. It is possible that teachers answer behavioral questions in a systematic way, and this may have truncated some of the variation in self-regulatory behavior and may be partially responsible for the three-class solutions. This may also explain, in part, why the three-class model has more stable 
Table 3 Latent growth class estimates for males $(N=10,293)$ and females $(N=9873)$

\begin{tabular}{|c|c|c|c|}
\hline & Estimate & Standard error & $p$ value \\
\hline \multicolumn{4}{|l|}{ Males } \\
\hline \multicolumn{4}{|c|}{ Class $1(42.2 \%)$} \\
\hline \multicolumn{4}{|c|}{ Means } \\
\hline I & 9.13 & 0.08 & 0.00 \\
\hline $\mathrm{S}$ & 0.04 & 0.04 & 0.32 \\
\hline \multicolumn{4}{|c|}{ Class $2(40.1 \%)$} \\
\hline \multicolumn{4}{|c|}{ Means } \\
\hline I & 11.62 & 0.06 & 0.00 \\
\hline $\mathrm{S}$ & -0.05 & 0.02 & 0.03 \\
\hline \multicolumn{4}{|c|}{ Class $3(17.7 \%)$} \\
\hline \multicolumn{4}{|c|}{ Means } \\
\hline I & 13.52 & 0.04 & 0.00 \\
\hline $\mathrm{S}$ & 0.12 & 0.02 & 0.00 \\
\hline \multicolumn{4}{|l|}{ Females } \\
\hline \multicolumn{4}{|c|}{ Class $1(58.1 \%)$} \\
\hline \multicolumn{4}{|c|}{ Means } \\
\hline I & 9.63 & 0.11 & 0.00 \\
\hline $\mathrm{S}$ & 0.02 & 0.06 & 0.75 \\
\hline \multicolumn{4}{|c|}{ Class $2(32.5 \%)$} \\
\hline \multicolumn{4}{|c|}{ Means } \\
\hline I & 11.95 & 0.07 & 0.00 \\
\hline $\mathrm{S}$ & 0.10 & 0.03 & 0.00 \\
\hline \multicolumn{4}{|c|}{ Class $3(9.4 \%)$} \\
\hline \multicolumn{4}{|c|}{ Means } \\
\hline I & 13.99 & 0.03 & 0.00 \\
\hline $\mathrm{S}$ & 0.14 & 0.01 & 0.00 \\
\hline
\end{tabular}

estimates than models with more classes. Further research regarding developmental trajectories in self-regulatory behavior across varied reporting sources is warranted.

Regarding sex differences in self-regulation, our findings indicate that males and females exhibit similar class structure and trajectory patterns in self-regulation, with the exception that the shape of the middle classes was different with males decreasing in self-regulation slightly and females increasingly slightly. In general, our results are in line with previous research $[29,30,34,47]$ and indicate that females exhibited a higher mean level of self-regulation across all waves. Furthermore, the female sample had a higher proportion of individuals in the highest self-regulatory class and a lower proportion of individuals in the lowest class as compared to male sample. A higher level of self-regulation in females has been a consistent finding regardless of reporting source and developmental period [19, 27, 30,39]. As such, the next step is to delve into the etiology of these sex differences. While it was beyond the scope of this paper to investigate the sources of self-regulation and its development, future research should examine the potential genetic and environmental contributions to sex differences in self-regulatory behaviors $[5,51,54]$. 
Finally, our latent class growth curve estimates support previous research indicating that self-regulation is a relatively stable trait $[27,28,39,57,58]$ and also provides evidence of absolute stability in the mean levels of self-regulation for both the lowest female and male classes. There were statistically significant and substantive differences in the initial levels (intercepts) of self-regulation both within and between sexes. This indicates that children in our sample entered kindergarten with pre-existing differences in self-regulation. However, regardless of class membership and regardless of sex, our sample of children exhibited little to no substantive change in mean self-regulation from kindergarten through fifth grade. The most substantive change in mean selfregulation was exhibited by the highest female class with a mean increase of 0.14 in self-regulation per year. ${ }^{3}$ The self-regulation scale ranges from 4 to 16 , and the cumulative mean growth effect for this high female class was 0.56 points from kindergarten through fifth grade, just over a half of a point increase in self-regulation. The middle female class, high male class, and middle male class also produced statistically significant slope estimates, but again, these were of small magnitude. Both the lowest female and male classes exhibited no statistically significant change in the mean level of self-regulation, demonstrating absolute stability for these classes. In sum, our data provide evidence of relative stability in self-regulation across class membership and sex from kindergarten through the fifth grade. Considering that there were different teachers reporting on student behavior at each wave, this level of stability is particularly noteworthy.

\section{Limitations}

While our findings are interesting and potentially valuable, limitations must be acknowledged, particularly with regard to the use of teacher reports. First, although teacher reports are said to be highly reliable $[10,26]$, we recognize that children may behave differently in the home environment than in the school environment. Given that there were no self-reports of self-regulation and that parent reports were only available for the kindergarten and first grade waves, we were limited to using teacher-reported self-regulation measures only. While research indicates that parent and self-reports of behavior often produce downwardly biased estimates [26, 59], we acknowledge that whenever possible, it is best to examine multiple reporting sources.

Second, the use of teacher reports may have affected the variation in the sample. Specifically, it is noted that teachers may evaluate student behavior in a methodological way. For example, a teacher may rank children on a continuum of good behavior to bad behavior and when reporting on an individual, they may use that continuum as a reference for how to categorize the child's behavior. In this way, teachers may rapidly and systematically evaluate behavior without noting important details and differences between children [10]. This quick, methodological approach to evaluating behavior may have constrained some variation in self-regulation. While this may not be true of all teachers, it is a possible concern and again points to the need for employing multiple reporting sources and for replication. Finally, it is important to note that our sample covers a relatively small window of time in the life-course, early through late

\footnotetext{
${ }_{3}^{3}$ While this was a statistically significant slope estimate, we acknowledge that it may be due in part to a large sample size.
} 
childhood, and that differences in self-regulation between sexes may emerge earlier in life, and the dynamics of self-regulatory patterns may change later in adolescence and adulthood.

Despite these limitations, the current study revealed two important findings. First, as found in several other studies, females exhibited a higher mean level of self-regulation initially and across each wave. The consistency of this finding is noteworthy and calls for further investigation regarding the sources behind self-regulatory behavior and whether these sources vary by sex. Second, our analyses revealed that self-regulation is a relatively stable trait, and that this stability does not vary across sex. In all three classes and in both samples, mean levels of self-regulation showed little to no change from kindergarten through the fifth grade, a time where self-regulatory behaviors are thought to be in flux.

This implies that problems with self-regulation can be identified early in the life course. Furthermore, without some form of intervention, these self-regulatory problems are likely to continue across childhood, becoming more stable as children age, particularly for those with the poorest levels of self-regulation. There are several programs that may help identify self-regulatory problems and prevent persistent problem behavior. Initiatives such as early family and parenting training work to help parents identify and prevent self-regulatory problems such as impulsivity, aggression, and oppositional behavior. A review from Piquero et al. [44] indicated that these programs are effective and that overall, recidivism rates of delinquency were lower in the experimental group receiving the parent/family training (33\%) than the control group (50\%). A metaanalysis by Piquero et al. [45] on programs targeting self-control in children under 10 years old reported that early intervention programs for self-control were effective in identifying behavioral problems, creating better self-control, and reducing delinquency, especially programs targeting young children, programs conducted in school settings, and programs which used video-taping, recording, and cognitive behavioral strategies.

While more research is needed, these studies support early intervention efforts for children exhibiting poor self-regulation. Since problems with self-regulation early in life are related to numerous issues later on in life, such as delinquency, substance abuse, poor performance in school, a lack of employment, and criminal involvement [2, 38, $46,52,64]$, it is vital that children with low self-regulation are identified, directed toward and receive proper intervention early in life.

\section{References}

1. Arneklev, B. J., Cochran, J. K., \& Gainey, R. R. (1998). Testing Gottfredson \& Hirschi's low self-control stability hypothesis: an exploratory study. American Journal of Criminal Justice, 23, 107-127.

2. Barkley, R. A. (2005). ADHD and the nature of self-control. New York: Guilford.

3. Beaver, K. M., \& Wright, J. P. (2007). The stability of low self-control from kindergarten through first grade. Journal of Crime and Justice, 30, 63-86.

4. Benes, K. M. (1995). Review of the social skills rating system. In Conoley \& Impara (Eds.), Twelfth mental measurements yearbook. Lincoln: Buros Institute of Mental Measurement.

5. Boisvert, D., Wright, J. P., Knopik, V., \& Vaske, J. (2013). A twin study of sex differences in self-control. Justice Quarterly, 30(3), 529-559. 
6. Broidy, L.M., Tremblay, R.E., Brame, B., Fergusson, D., Horwood, J.L., Laird, R., ..., \& Vitaro, F. (2003). Developmental trajectories of childhood disruptive behaviors and adolescent delinquency: a sixsite, cross-national study. Developmental Psychology, 39, 222-245.

7. Bronson, M. B. (2000). Self-regulation in early childhood. New York: The Guilford Press.

8. Burt, C. H., Sweeten, G., \& Simons, R. L. (2014). Self-control through emerging adulthood: instability, multidimensionality, and criminological significance. Criminology, 52(3), 450-487.

9. Burt, C. H., Simons, R. L., \& Simons, L. G. (2006). A longitudinal test of the effects of parenting and the stability of self-control: negative evidence for the general theory of crime. Criminology, 44, 353-396.

10. Cairns, R. B., \& Cairns, B. D. (1994). Lifelines and risks: pathways of youth in our time. New York: Cambridge University Press.

11. Caspi, A., \& Moffit, T. E. (1995). The continuity of maladaptive behavior: from description to understanding in the study of antisocial behavior. In D. Cicchetti \& D. Cohen (Eds.), Manual of developmental psychopathology (Vol. 2, pp. 472-511). New York: Wiley.

12. Chapple, C. L., \& Johnson, K. A. (2007). Gender differences in impulsivity. Youth Violence and Juvenile Justice, 5(3), 221-234.

13. Committee on Integrating the Science of Early Childhood Development. (2000). From neurons to neighborhoods: the science of early childhood development. Washington, DC: National Academy Press.

14. Côté, S., Tremblay, R. E., Nagin, D., Zoccolillo, \& Vitaro, F. (2002). The development of impulsivity, fearfulness, and helpfulness during childhood: patterns of consistency and change in the trajectories of boys and girls. Journal of Child Psychology and Psychiatry, 43, 609-618.

15. Cowell, P. E., Turetsky, B. I., Gur, R. C., Grossman, R. I., Shtasel, D. L., \& Gur, R. E. (1994). Sex differences in aging of the human frontal and temporal lobes. The Journal of Neuroscience, 14, 47484755 .

16. de Kemp, R. A. T., Vermulst, A. A., Finkenauer, C., Scholte, R. H. J., Overbeek, G., Rommes, E. W. M., \& Engels, R. C. M. E. (2009). Self-control and early adolescent antisocial behavior: a longitudinal analysis. Journal of Early Adolescence, 29, 497-517.

17. Dekker, M. C., Ferdinand, R. F., van Lang, N. D. J., Bongers, I. L., van der Ende, J., \& Verhulst, F. C. (2007). Developmental trajectories of depressive symptoms from childhood to late adolescence: gender differences and adult outcome. Journal of Child Psychology and Psychiatry, 48, 657-666.

18. Demaray, M. K., Ruffalo, S. L., Carlson, J., \& Busse, R. T. (1995). Social skills assessment: a comparative evaluation of six published rating scales. School Psychology Review, 24(4), 648-671.

19. Else-Quest, N. M., Hyde- Shibley, J., Hill-Goldsmith, H., \& VanHulle, C. A. (2006). Gender differences in temperament: a meta-analysis. Psychological Bulletin, 132(1), 33-72.

20. Fontaine, N., Carbonneau, R., Vitaro, F., Barker, E. D., \& Tremblay, R. E. (2004). Research review: a critical review of studies on the developmental trajectories of antisocial behavior in females. Journal of Child Psychology and Psychiatry, 50, 363-385.

21. Gottfredson, M., \& Hirschi, T. (1990). A general theory of crime. Stanford: Standford University Press.

22. Grasmick, H. G., Tittle, C. R., Bursik, R. J., \& Arneklev, B. J. (1993). Testing the core empirical implications of Gottfredson and Hirschi's general theory of crime. Journal of Research in Crime and Delinquency, 30(1), 5-29.

23. Gresham, F. M., \& Elliot, S. N. (1990). Social skills rating system. Circle Pines: American Guidance Service.

24. Hagan, J., Gillis, A. R., \& Simpson, J. (1985). The class structure of gender and delinquency: toward a power-control theory of common delinquency behaviors. American Journal of Sociology, 90, 1151-1178.

25. Hagan, J., Simpson, J., \& Gillis, A. R. (1987). Class in the household: a power-control theory of gender and delinquency. American Journal of Sociology, 92, 788-816.

26. Harris, J. R. (1998). The nurture assumption: why children turn out the way they do. New York: The Free Press.

27. Hay, C., \& Forrest, W. (2006). The development of self-control: examining self-control theory's stability thesis. Criminology, 44(4), 739-774.

28. Higgins, G. E., Jennings, W. G., Tewksbury, R., \& Gibson, C. L. (2009). Exploring the link between low self-control and violent victimization trajectories in adolescents. Criminal Justice \& Behavior, 36, 10701084.

29. Kochanska, G., Murray, K., \& Coy, K. C. (1997). Inhibitory control as a contributor to conscience in childhood: from toddler to early school age. Child Development, 68(2), 263-277.

30. Kochanska, G., Murray, K. T., \& Harlan, E. T. (2000). Effortful control in early childhood: continuity and change, antecedents, and implications for social development. Developmental Psychology, 36(2), 220.

31. Lamont, A., \& Van Horn, L. M. (2013). Heterogeneity in parent-reported social skill development in early elementary school children. Social Development, 22(2), 384-405. 
32. Lenroot, R. K., Gogtay, N., Greenstein, D. K., Wells, E. M., Wallace, G. L., Clasen, L. S., ..., \& Giedd, J. N. (2007). Sexual dimorphism of brain developmental trajectories during childhood and adolescence. Neuroimage, 36, 1065-1073.

33. Lenroot, R. K., \& Giedd, J. N. (2010). Sex differences in the adolescent brain. Brain and Cognition, 72, 46-55.

34. Li-Grining, C. P. (2007). Effortful control among low-income preschoolers in three cities: stability, change, and individual differences. Developmental Psychology, 43(1), 208-221.

35. Lyon, M. A., Albertus, C., BffiKinbine, J., \& Naibi, J. (1996). A validity study of the social skills rating system-teacher version with disabled and nondisabled preschool children. Perceptual and Motor Skills, $83,307-316$.

36. McGloin, J. M., Sullivan, C. J., \& Bacon, S. (2008). Investigating the stability of co-offending and cooffenders among a sample of youthful offenders. Criminology, 46, 155-187.

37. Moilanen, K. L., Shaw, D. S., Dishion, T. J., Gardner, F., \& Wilson, M. (2010). Predictors of longitudinal growth in inhibitory control in early childhood. Social Development, 19(2), 326-347.

38. Monahan, K. C., Steinberg, L., Cauffman, E., \& Mulvey, E. P. (2009). Trajectories of antisocial behavior and psychosocial maturity from adolescence to young adulthood. Developmental Psychology, 45(6), 1654.

39. Murphy, B. C., Eisenberg, N., Fabes, R. A., Shepard, S., \& Guthrie, I. K. (1999). Consistency and change in children's emotionality and regulation: a longitudinal study. Merrill-Palmer Quarterly, 45(3), 413-444.

40. Muthén, B. (2004). Latent variable analysis. The Sage handbook of quantitative methodology for the social sciences (pp. 345-368). Thousand Oaks: Sage Publications.

41. Na, C., \& Paternoster, R. (2012). Can self-control change substantially over time? Rethinking the relationship between self- and social control. Criminology, 50(2), 427-462.

42. Nylund, K., Asparouhov, T., \& Muthen, B. (2007). Deciding on the number of classes in latent class analysis and growth mixture modeling: a Monte Carlo simulation study. Structural Equation Modeling: An Interdisciplinary Journal, 14, 535-569.

43. Piquero, A. R., Brame, R., \& Moffitt, T. E. (2005). Extending the study of continuity and change: gender differences in the linkage between adolescent and adult offending. Journal of Quantitative Criminology, 21, 219-243.

44. Piquero, A. R., Farrington, D. P., Welsh, B. C., Tremblay, R., \& Jennings, W. G. (2009). Effects of early family/parent training programs on antisocial behavior and delinquency. Journal of Experimental Criminology, 5(2), 83-120.

45. Piquero, A. R., Jennings, W. G., \& Farrington, D. P. (2010). On the malleability of self-control: theoretical and policy implications regarding a general theory of crime. Justice Quarterly, 27(6), 803-834.

46. Pratt, T. C., \& Cullen, F. T. (2000). The empirical status of Gottfredson \& Hirschi's general theory of crime: a meta-analysis. Criminology, 38, 931-964.

47. Raffaelli, M., Crockett, L., \& Shen, Y-L. (2005). Developmental stability and chance in self-regulation from childhood to adolescence. The Journal of Genetic Psychology, 166(1), 54-75.

48. Raikes, H. A., Robinson, J. L., Bradley, R. H., Raikes, H. H., \& Ayoub, C. C. (2007). Developmental trends in self-regulation among low-income toddlers. Social Development, 16(1), 128-149.

49. Ray, J. V., Jones, S., Loughran, T. A., \& Jennings, W. G. (2013). Testing the stability of self-control: identifying unique developmental patterns and associated risk factors. Criminal Justice and Behavior, 40(6), 588-607.

50. Raznahan, A., Lee, Y., Stidd, R., Long, R., Greenstein, D., Clasen, L., Addington, A., ..., \& Giedd, J. N. (2010). Longitudinally mapping the influence of sex and androgen signaling on the dynamics of human cortical maturation in adolescence. Proceedings of the National Academy of Sciences, 107, 16988-16993.

51. Rhee, S. H., Waldman, I. D., Hay, D. A., \& Levy, F. (1999). Sex differences in genetic and environmental influences on DSM-III-R attention-deficit/hyperactivity disorder. Journal of Abnormal Psychology, 108, $24-41$.

52. Tan, P. Z., Armstrong, L. M., \& Cole, P. M. (2013). Relations between temperament and anger regulation over early childhood. Social Development, 22(4), 755-772.

53. Turner, M. G., \& Piquero, A. R. (2002). The stability of self-control. Journal of Criminal Justice, 30, 457471.

54. van den Oord, E., Verhulst, F. C., \& Boomsma, D. I. (1996). A genetic study of maternal and paternal ratings of problem behaviors in 3-year-old twins. Journal of Abnormal Psychology, 105(3), 349-357.

55. Vaske, J., Galyean, K., \& Cullen, F. T. (2011). Toward a biosocial theory of offender rehabilitation: why does cognitive-behavioral therapy work? Journal of Criminal Justice, 39, 90-102.

56. Vaske, J., Ward, J. T., Boisvert, D., \& Wright, J. P. (2012). The stability of risk-seeking from adolescence to emerging adulthood. Journal of Criminal Justice, 40, 313-322. 
57. Vaughn, M. G., DeLisi, M., Beaver, K. M., \& Wright, J. P. (2009). Identifying latent classes of behavioral risk based on early childhood manifestations of self-control. Youth Violence and Juvenile Justice, $7(1), 16-31$.

58. Vazsonyi, A. T., \& Huang, L. (2010). Where self-control comes from: on the development of self-control and its relationship to deviance over time. Developmental Psychology, 46, 245-257.

59. Verhust, F. C., \& Van e Ende, J. (1992). Agreement between parents' reports and adolescents' self-reports of problem behavior. Journal of Child Psychology and Psychiatry, and Allied Disciplines, 33, 1011-1023.

60. Vermunt, J. K., \& Magidson, J. (2003). Latent class models for classification. Computational Statistics \& Data Analysis, 41(3), 531-537.

61. Wills, T. A., Ainette, M. G., Mendoza, D., Gibbons, F. X., \& Brody, G. H. (2007). Self-control, symptomatology, and substance use precursors: test of a theoretical model in a community sample of 9year-old children. Psychology of Addictive Behaviors, 21, 205-215.

62. Winfree, L. T., Taylor, T. J., He, N., \& Esbensen, F. (2006). Self-control and variability over time: multivariate results using a 5-year, multisite panel of youths. Crime \& Delinquency, 52, 253-286.

63. Wright, J. P., \& Beaver, K. M. (2005). Do parents matter in creating self-control in their children? A genetically informed test of Gottfredson \& Hirschi's theory of low self-control. Criminology, 43(4), 11691202.

64. Zhou, Q., Hofer, C., Eisenburg, N., Reiser, M., Spinrad, T. L., \& Fabes, R. A. (2007). The development trajectories of attention focusing, attentional and behavioral persistence, and externalizing problems during school-age years. Developmental Psychology, 43, 369-385. 